\title{
Apolipoprotein E Deficiency in Mice: Gene Replacement and Prevention of Atherosclerosis Using Adenovirus Vectors
}

Vikram S. Kashyap, Silvia Santamarina-Fojo, David R. Brown, Catherine L. Parrott, Deborah Applebaum-Bowden, Susan Meyn, Glenda Talley, Beverly Paigen, ${ }^{*}$ Nobuyo Maeda, ${ }^{\star}$ and H. Bryan Brewer, Jr.

National Institutes of Health, National Heart, Lung, and Blood Institute, Molecular Disease Branch, Bethesda, Maryland 20892;

* Jackson Laboratory, Bar Harbor, Maine 04609; and ${ }^{\ddagger}$ University of North Carolina School of Medicine, Chapel Hill,

North Carolina 37599

\begin{abstract}
Apolipoprotein E (apoE)-deficient mice develop marked hyperlipidemia as well as atherosclerosis and thus are an excellent animal model for evaluating the potential for gene therapy in human genetic dyslipoproteinemias. Recombinant adenovirus containing either human apoE (rAdv.apoE) or the reporter gene luciferase (rAdv.luc) were generated and infused intravenously in apoE-deficient mice with preinfusion plasma total cholesterol of $644 \pm 149 \mathrm{mg} / \mathrm{dl}$ and cholesterol rich VLDL/IDL. After a single infusion of rAdv.apoE, plasma concentrations of human apoE ranging from 1.5 to $650 \mathrm{mg} / \mathrm{dl}$ were achieved. Adenovirus-mediated apoE replacement resulted in normalization of the lipid and lipoprotein profile with markedly decreased total cholesterol $(103 \pm 18 \mathrm{mg} / \mathrm{dl})$, VLDL, IDL, and LDL, as well as increased HDL. Measurement of aortic atherosclerosis 1 mo after adenoviral infusion demonstrated a marked reduction in the mean lesion area of mice infused with rAdv.apoE $(58 \pm 8$ $\times 10^{3}{\mu \mathrm{m}^{2}}^{2}$ ) when compared with control mice infused with rAdv.luc $\left(161 \pm 19 \times 10^{3} \mu^{2} ; P<0.0001\right)$. Thus, apoE expression for 4 wk was sufficient to markedly reduce atherosclerosis, demonstrating the feasibility of gene therapy for correction of genetic hyperlipidemias resulting in atherosclerosis. The combined use of adenovirus vectors and the apoE-deficient mouse represents a new in vivo approach that will permit rapid screening of candidate genes for the prevention of atherosclerosis. (J. Clin. Invest. 1995. 96:1612-1620.) Key words: apolipoprotein $\mathbf{E} \cdot$ gene therapy - atherogenesis $\bullet$ in vivo $\bullet$ adenoviridae
\end{abstract}

\section{Introduction}

Apolipoprotein E (apoE), a 36-kD plasma glycoapolipoprotein, plays a key role in lipoprotein metabolism by facilitating the cellular uptake of remnants of triglyceride-rich chylomicrons and VLDL (for review see references 1 and 2). Human apoE is polymorphic and consists of three major isoproteins of which apoE-3 is the most common. In lipoprotein metabolism, apoE

Address correspondence to $\mathrm{H}$. Bryan Brewer, Jr., National Institutes of Health, Molecular Disease Branch, National Heart, Lung, and Blood Institute, Building 10, Room 7N115, 10 Center Drive MSC 1666, Bethesda, MD 20892. Phone: 301-496-5095; FAX: 301-402-0190.

Received for publication 29 March 1995 and accepted in revised form 30 May 1995.

The Journal of Clinical Investigation, Inc.

Volume 96, September 1995, 1612-1620 serves as a ligand on lipoprotein particles for the LDL receptor and has also been proposed as a ligand for LDL receptor-related protein, the putative remnant receptor, as well as the VLDL receptor (3-8). The important role that apoE plays in facilitating lipoprotein transport has been established in part by the identification of patients with apoE deficiency (9-13) or, more commonly, patients with a structural defect in apoE that results in decreased affinity for the lipoprotein receptors (14-17). A defect in the function of apoE leads to delayed plasma clearance of remnants of triglyceride-rich lipoproteins and the development of dysbetalipoproteinemia or type III hyperlipoproteinemia. The majority of patients with type III hyperlipoproteinemia have the apoE-2 isoform which has reduced binding to the lipoprotein receptors. Type III hyperlipoproteinemia is characterized by elevated plasma levels of cholesterol, triglycerides, atherogenic cholesterol rich remnants of chylomicrons, and VLDL, as well as by the presence of xanthomas and development of premature cardiovascular disease.

A mouse model for apoE deficiency has been developed using homologous recombination with apoE-targeted gene disruption in embryonic stem cells (18). The apoE-deficient mice develop marked hypercholesterolemia with total cholesterol levels five- to six-fold greater than control mice $(19,20)$. These apoE-deficient mice have a dramatic shift in plasma lipoproteins from HDL, the major lipoprotein in control mice, to cholesterolenriched remnants of chylomicrons and VLDL. Of particular interest in the apoE-deficient mice is the development of spontaneous atherosclerosis on a normal chow diet (20-22). The apoE-deficient mouse represents a unique model to study gene replacement of a plasma apolipoprotein for correction of a genetic dyslipoproteinemia. The correction of the apoE deficiency in this animal model presents several interesting challenges. For apoE to function in facilitating the clearance of lipoprotein remnants, gene replacement must be followed by synthesis and secretion of the apolipoprotein in a pathway that will permit it to become associated with both hepatic proteoglycans and plasma lipoproteins. In addition, to achieve replacement of apoE at levels observed in normal control animals, it must be expressed in the milligrams per deciliter level in plasma, that has not been readily achieved in previous gene replacement studies. A recent study indicates that bone marrow transplantation with replacement of apoE by using apoE-expressing myeloid cells in apoEdeficient mice may correct the metabolic defect as well the dietenhanced atherosclerosis in these animals (23). In humans and normal mice, however, the major site of synthesis of apoE appears to be the liver $(2,24)$.

In this report, we describe the successful correction of apoE deficiency in apoE-deficient mice by using an alternative approach involving systemic delivery to mouse liver of recombi- 

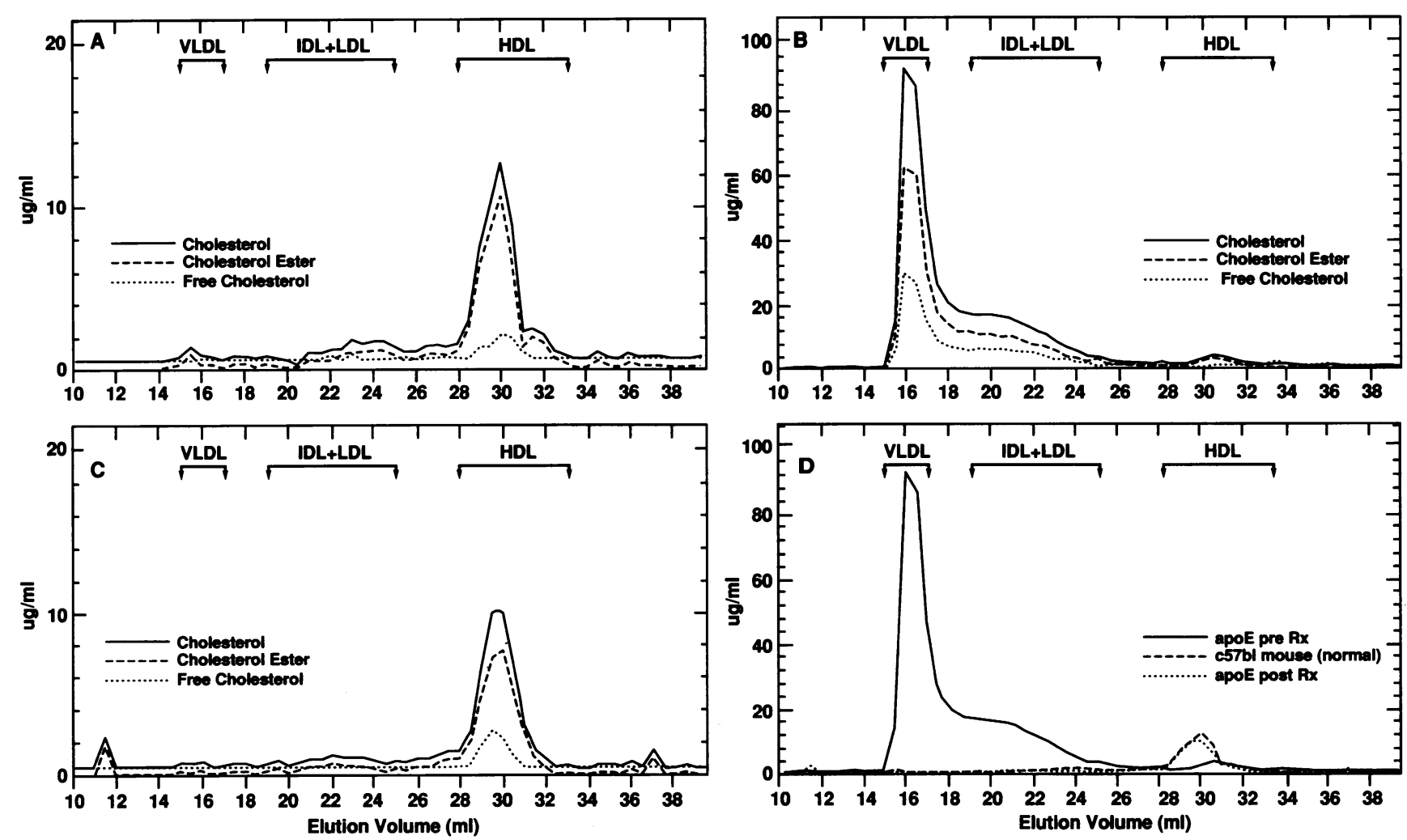

Figure 1. Lipoprotein profiles. Lipoprotein analysis by FPLC of mouse plasma samples. $(A)$ Control C57 black mouse, $(B)$ apoE-deficient mouse, $(C)$ apoE-deficient mouse $4 \mathrm{~d}$ after rAdv.apoE infusion, $(D)$ summary of cholesterol curves from $A-C$. Note the different vertical axes and the superimposition of the cholesterol profile of the apoE-deficient mouse after rAdv.apoE injection and that of the control mouse $(D)$. Relative elution positions of different lipoproteins on FPLC are indicated in the panels.

nant adenovirus vectors expressing human apoE. Using this approach, the marked hypercholesterolemia and abnormal lipoprotein profile in apoE-deficient mice were normalized and plasma apoE levels ranging from a normal level of 3-4 $\mathrm{mg} / \mathrm{dl}$ to $650 \mathrm{mg} / \mathrm{dl}$ were achieved. apoE expression for $4 \mathrm{wk}$ resulted in a significant reduction of aortic atherosclerotic mean lesion area when compared with control apoE-deficient mice. These combined results provide definitive evidence for the feasibility of gene replacement as well as modulation of the atherosclerotic process in the genetic dyslipoproteinemias resulting from apolipoprotein gene defects.

\section{Methods}

Generation of recombinant adenovirus. A full-length human apoE cDNA (apoE3 isoform) $(25,26)$ was cloned into a pUC18-derived plasmid vector which contained cytomegalovirus (CMV) ${ }^{1}$ enhancer and promoter elements upstream and designated pCMV12apoE. The 1.1-kb apoE gene was sequenced using the Sanger dideoxynucleotide method (27) and the proper orientation was confirmed.

Human embryonic kidney 293 cells (28) of low passage number were used for cell culture studies (American Type Culture Collection, Rockville, MD). The plasmid construct pCMV12apoE was transfected using calcium phosphate (29) to determine functionality, and apoE was identified in the culture media by an apoE ELISA and immunoblotting with an apoE monospecific antibody. The apoE gene was subcloned into a shuttle vector ( $\mathrm{pAd} 12 \mathrm{apoE}$ ) containing CMV enhancer and promoter elements, an SV40 polyadenylation signal, and the El region of the human adenovirus (Ad5) (30). Recombinant E1-deleted adenovirus

1. Abbreviations used in this paper: CMV, cytomegalovirus; FPLC, fast protein liquid chromatography.

Table I. Plasma Lipids and Lipoproteins in apoE-deficient and Normal Mice

\begin{tabular}{lcccccc}
\hline & TC & TG & PL & CE & FC & HDL-C \\
\hline & & & & $m g / d l$ & & \\
& & & & & & \\
ApoE-deficient $(n=15)$ & $644 \pm 149^{*}$ & $111 \pm 74$ & $341 \pm 82^{*}$ & $420 \pm 121^{*}$ & $223 \pm 49 *$ & $23 \pm 6 *(n=7)$ \\
Controls $(n=15)$ & $103 \pm 13$ & $76 \pm 17$ & $185 \pm 17$ & $77 \pm 10$ & $26 \pm 4$ & $69 \pm 3 \quad(n=7)$ \\
& & & & & &
\end{tabular}

The mean \pm SD of all lipid values are shown. $T C$, total cholesterol; $T G$, triglycerides; $P L$, phospholipids; $C E$, cholesterol ester; $F C$, free cholesterol. $* P<0.001$. 


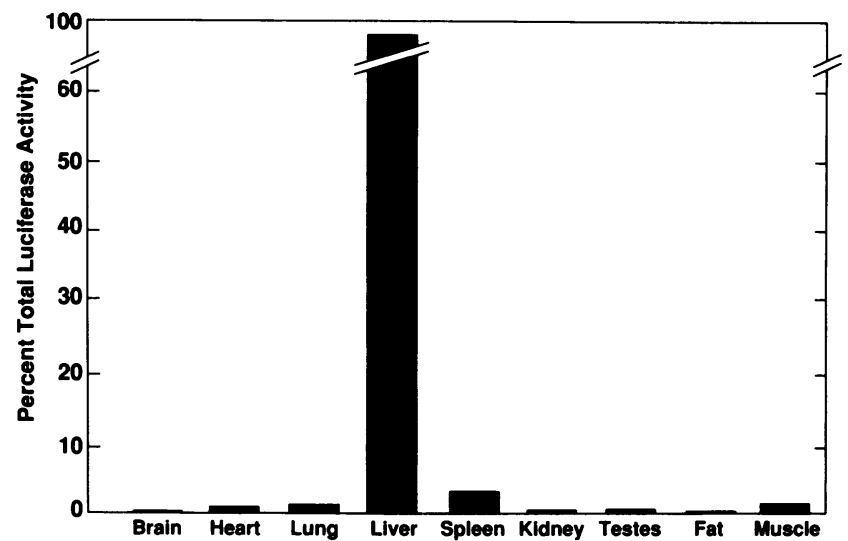

Figure 2. Relative tissue distribution of luciferase activity. Organs were harvested from C57 black mice $(n=3) 4 \mathrm{~d}$ after rAdv.luc injection and the assay performed on 100-mg samples of homogenized tissues as described in Methods. Luciferase activity is expressed as a percentage of total activity present in organs analyzed.

was generated after cotransfection of pAd12apoE and pJM17 (Ad5 genome) in 293 cells as described previously (31). The recombinant virus was propagated in 293 cells and purified by cesium chloride density ultracentrifugation. The purified virus designated rAdv.apoE was titered and diluted in $\mathbf{0 . 2 \%}$ mouse albumin (Sigma Chemical Co., St. Louis, MO) before infusion into the animals. The same methodology was performed to generate the recombinant adenovirus containing the luciferase gene (32), designated rAdv.luc.

apoE-deficient mice. apoE-deficient mice, obtained from University of North Carolina, were bred and housed at the National Institutes of Health (NIH) under protocols approved by the Animal Care and Use Committee of the National Heart, Lung, and Blood Institute. Animals had free access to food (NIH 07 chow diet, $4.5 \%$ fat, $0 \%$ cholesterol; Zeigler Brothers Co., Gardners, PA) and water. All animal procedures were performed according to NIH guidelines (33). Age- and weightmatched mice ( $\sim 4$ mo and 25 grams, respectively) of both sexes re-

Table II. Plasma apoE Levels in Control and apoE-deficient Mice

\begin{tabular}{lc}
\hline rAdv.apoE-treated mice & apoE \\
\hline & $m g / d l$ \\
Low expressors & \\
E-1 & 1.5 \\
E-2 & 2.9 \\
E-3 & 6.0 \\
E-4 & 7.0 \\
E-5 & 13.0 \\
E-6 & 14.0 \\
E-7 & 35.0 \\
High expressors & \\
E-8 & 536.0 \\
E-9 & 648.0 \\
Control mice & \\
C57black $(n=4)$ & $7.0 \pm 1.6$ \\
\hline
\end{tabular}

apoE quantitation was determined by ELISA and plasma samples were assayed $4 \mathrm{~d}$ after either $2 \times 10^{8}$ or $3 \times 10^{9}$ pfu rAdv.apoE injection in low and high expressor apoE-deficient mice, respectively.

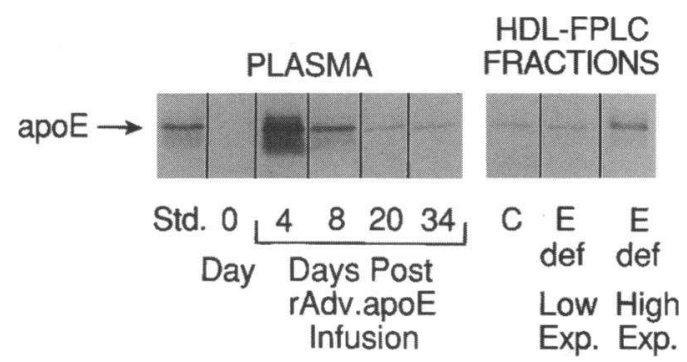

Figure 3. apoE immunoblot of mouse plasma and FPLC lipoprotein fractions. Analysis of apoE plasma expression before (day 0 ) and after (days 4, 8, 20, and 34) rAdv.apoE infusion revealed the presence of an intact $36-\mathrm{kD}$ apoE band. Analyses of the individual fractions across the FPLC elution profile demonstrated apoE associated primarily with mouse HDL in control $(C)$ as well as low ( $E$ def Low Exp.) and high expressing ( $E$ def High exp.) apoE-deficient animals after rAdv.apoE infusion. Standard (Std.) is purified human apoE (10 $\mathrm{ng}$ ).

ceived intravenous injections of adenovirus through the saphenous vein. All plasma samples were drawn at 11 a.m. after a 4-h fast.

Luciferase assay. Animals were killed $4 \mathrm{~d}$ after rAdv.luc virus infusion, and the individual organ tissues were frozen. The thawed samples were homogenized using a hand-held homogenizer (Omni International, Marietta, GA), subjected to three freeze/thaw cycles, and centrifuged. The supernatants were assayed on a luminometer (Monolight 2010; Analytic Luminescence Laboratory, San Diego, CA) using luciferin substrate (34).

Plasma lipid, lipoprotein, and apolipoprotein analyses. Total cholesterol, triglycerides, phospholipids, and free cholesterol were assayed using enzymic kits from Sigma Diagnostics (St. Louis, MO) and Wako Chemicals USA, Inc. (Richmond, VA). Assays were performed on 10$\mu l$ aliquots of fasting plasma samples using the COBAS MIRA Plus automated chemistry analyzer (Roche Diagnostic Systems, Inc., Branchburg, NJ). Cholesterol ester values were calculated as the difference between total cholesterol and free cholesterol concentrations (35). HDL-cholesterol was measured via dextran sulfate (Ciba-Corning, Oberlin, $\mathrm{OH}$ ) precipitation. Plasma lipoproteins were analyzed by fast protein liquid chromatography (FPLC) using two Superose 6 columns in series (36) (Pharmacia LKB Biotechnology, Inc., Piscataway, NJ). 50$\mu \mathrm{l}$ plasma samples from control and apoE-deficient mice before and after adenoviral infusion were analyzed individually. Lipoproteins were eluted at a constant flow rate of $0.3 \mathrm{ml} / \mathrm{min}$ with PBS buffer containing $1 \mathrm{mM}$ EDTA and $0.02 \%$ sodium azide. FPLC profiles of individual mice are shown and are representative of 12 analyses obtained during the course of the study (Fig. 1).

Human apoE in mouse plasma was quantitated by a sandwich ELISA using microtiter immunoassay plates (Immulon 1; Dynatech Laboratories, Chantilly, VA) coated with a monoclonal apoE antibody ABE2 (University of Ottawa Heart Institute, Ottawa, Ontario, Canada) for capture. Purified mouse apoE and recombinant human apoE3 were quantitated by amino acid analysis. Purified recombinant human apoE3 in progressive dilutions in apoE-deficient human plasma was used to generate a standard curve from 0 to $200 \mathrm{ng} / \mathrm{ml}$. A polyclonal rabbit apoE antibody followed by a goat anti-rabbit peroxidase-conjugated antibody was used for detection. The within-run coefficient of variation of the apoE assays was $12 \%$. Mouse apoE quantitation was performed by computerized densitometry of apoE immunoreactive bands on protein immunoblots as described below. Purified mouse apoE was used to generate a standard curve on each gel from 5 to $40 \mathrm{ng}$ and a polyclonal apoE antibody (Biodesign International, Kennebunkport, ME) was used for detection.

Immunoblotting was performed on a $10 \%$ Tris glycine gel (Novex, San Diego, CA) using standard Laemmli buffer containing SDS and mercaptoethanol. The samples ( $1 \mu \mathrm{l}$ of plasma diluted 10 -fold with 
Table III. Plasma Lipids and Lipoproteins after Adenoviral Injection

\begin{tabular}{lrrrrrr}
\hline & TC & TG & PL & CE & FC & HDL-C \\
\hline & & & & $m g / d l$ & & \\
rAdv.luc $(n=8)$ & $739 \pm 165$ & $130 \pm 44$ & $428 \pm 129$ & $492 \pm 105$ & $247 \pm 90$ & $21 \pm 6$ \\
rAdv.apoE $(n=7)$ & $103 \pm 18^{*}$ & $97 \pm 32$ & $194 \pm 34^{*}$ & $52 \pm 10^{*}$ & $52 \pm 12^{*}$ & $85 \pm 44^{\ddagger}$ \\
Controls $(n=15)$ & $103 \pm 13$ & $76 \pm 17$ & $185 \pm 17$ & $77 \pm 10$ & $26 \pm 4$ & $69 \pm 3$ \\
\hline
\end{tabular}

Plasma samples were assayed $4 \mathrm{~d}$ after either rAdv.luc or rAdv.apoE injection in apoE-deficient mice. Comparison of these two groups was used for statistical analysis. Controls represent values in noninjected C57 black mice. ${ }^{*} P<0.001 ;{ }^{\ddagger} P<0.002$.

PBS) were electophoresed for $1.5 \mathrm{~h}$ and transferred to an Immobilon polyvinylidene difluoride membrane (Millipore Corp., Bedford, MA) for $2 \mathrm{~h}$. Blocking was performed with $3 \%$ BSA followed by incubation with a human apoE specific monoclonal antibody (ABE 1, University of Ottawa Heart Institute) for $12 \mathrm{~h}$. Secondary antibody and detection were performed with a silver enhancement of a gold-labeled anti-mouse antibody using a 2-h incubation (Auroprobe; Amersham International, Buckinghamshire, United Kingdom).

Evaluation of atherosclerosis. The heart and attached section of ascending aorta were dissected en bloc and placed in $0.9 \%$ saline for 1 $\mathrm{h}$ followed by fixing in $4 \%$ formaldehyde for $24 \mathrm{~h}$ and then $10 \%$ formaldehyde for $5 \mathrm{~d}$ as described previously (37). The specimens were embedded in $25 \%$ gelatin and then sectioned using a cryostat at $-25^{\circ} \mathrm{C}$. The aortic root and ascending aorta were sectioned at a thickness of 10 $\mu \mathrm{m}$ and alternate sections were saved on slides and stained with Oilred-O for neutral lipids and hematoxylin for nucleic tissue. Five sections per animal were evaluated for the cross-sectional area of lesions from the aortic root for a distance of $\sim 350 \mu \mathrm{m}$ at $80 \mu \mathrm{m}$ intervals $(37,38)$. The groups were statistically analyzed using unpaired Student's $t$ test.

\section{Results}

The plasma lipids and lipoproteins present in the apoE-deficient and control C57black mice are summarized in Table I. When compared with control mice, the apoE-deficient mice were markedly hyperlipidemic with plasma total cholesterol, cholesterol ester, and free cholesterol levels approximately sixfold greater than control mice and plasma triglycerides and phospholipids twofold greater. Furthermore, HDL is reduced to onethird of the normal levels. The lipoprotein profiles determined by FPLC for the control and apoE-deficient mice are shown in Fig. $1, A$ and $B$. In control mice (Fig. $1 A$ ), the lipoprotein profile revealed HDL as the predominant lipoprotein with only small amounts of VLDL and LDL. In contrast, the major lipoproteins in the apoE-deficient mice (Fig. $1 B$ ) were VLDL and IDL with a significant reduction in HDL. The combined lipids and lipoprotein profiles in the apoE-deficient mice are consistent with delayed clearance of triglyceride-rich lipoproteins leading to markedly elevated cholesterol-enriched remnant lipoproteins.

To determine the efficacy of apoE gene replacement, apoEdeficient mice were infused intravenously with a recombinant adenovirus containing the apoE gene designated rAdv.apoE driven by a CMV promoter and enhancer. A similar recombinant adenovirus containing the luciferase gene (rAdv.luc) was used as a control for viral-induced changes in plasma lipoproteins. The recombinant luciferase adenovirus construct was also used for the determination of the tissue distribution of the adenoviral-mediated gene delivery because of the availability of a sensitive quantitative assay (39). The tissue distribution of transgene expression after intravenous rAdv.luc infusion is summarized in Fig. 2. Consistent with previous reports (40-42) which have demonstrated expression of the transgene in virtually all the hepatocytes examined, the liver was the major organ

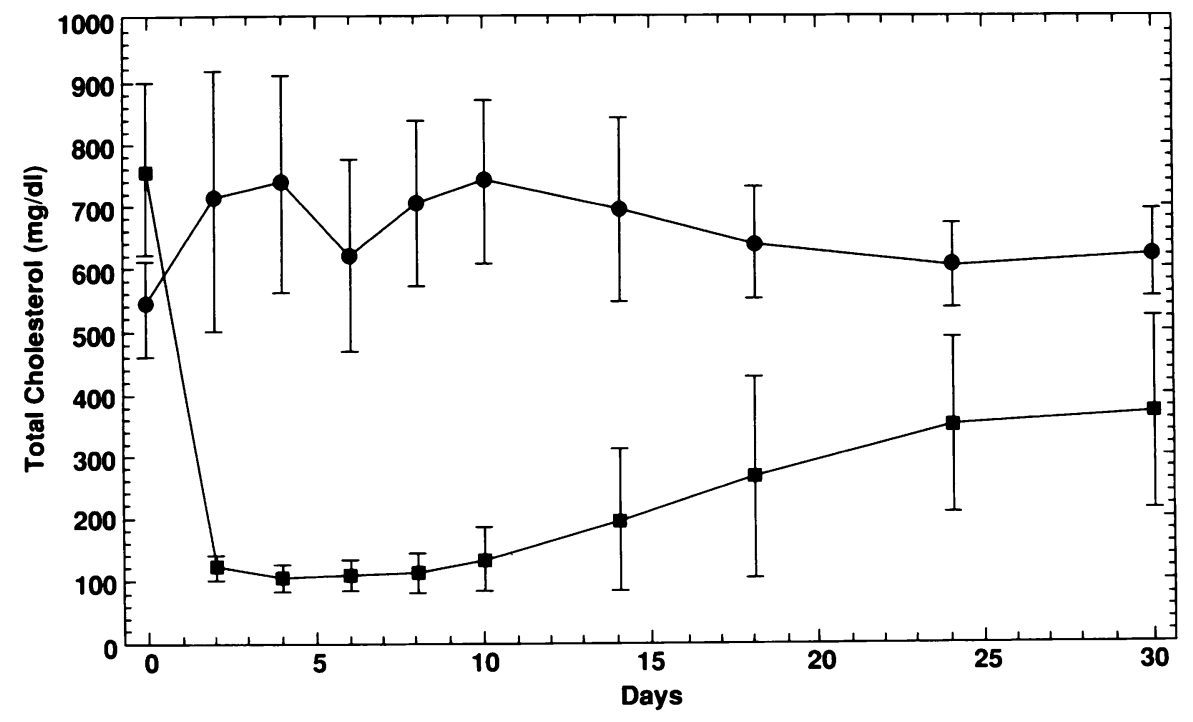

Figure 4. Plasma cholesterol values after adenoviral infusion. Cholesterol values in apoE-deficient mice after either rAdv.luc (closed circles, $n=8$ ) or rAdv.apoE (closed squares, $n=7$ ) infusion. Values are mean $\pm \mathrm{SD}$. 


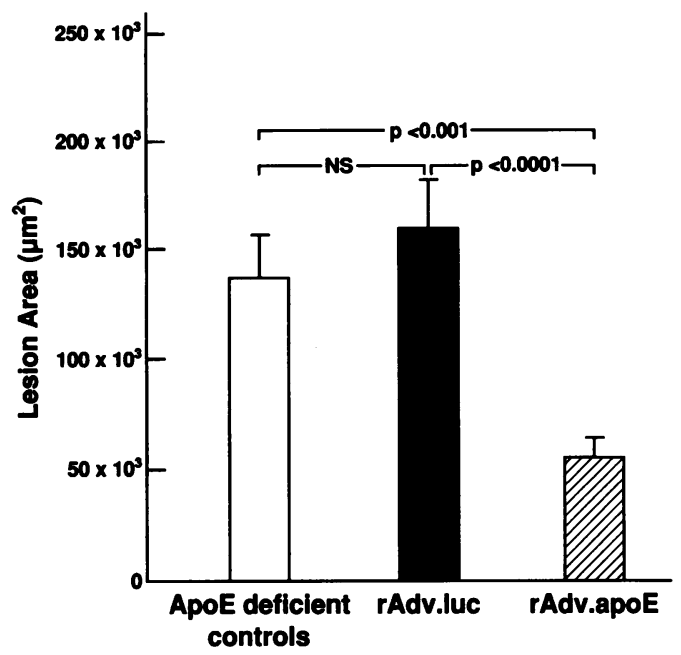

Figure 5. Aortic atherosclerosis after adenoviral infusion. 10 apoEdeficient mice on a normal chow diet $(3.4 \%$ fat, $0 \%$ cholesterol) were used for determination of total lesion area in the ascending aorta. Aortic sections from apoE-deficient mice at 5 mo of age served as controls ( $n$ $=15$ sections ). 4-mo-old apoE-deficient mice were infused with either rAdv.luc or rAdv.apoE and killed 1 mo later at the age of 5 mo. Aortic sections harvested from mice infused with $\mathrm{rAdv}$.apoE ( $n=20$ sections) had markedly lower aortic atherosclerosis when compared with apoEdeficient mice after infusion with rAdv.luc ( $n=15$ sections, $P$ $<0.0001)$. Error bars indicate SEM.

of luciferase transgene expression. Low level expression of the luciferase transgene was also detected in the spleen, lung, and heart.

Infusion of apoE-deficient mice with either $2 \times 10^{8}$ or 3 $\times 10^{9} \mathrm{pfu}$ of rAdv.apoE resulted in low and high levels of expression of plasma apoE, respectively. At $4 \mathrm{~d}$ after injection, the plasma apoE levels ranged in the low expressors from 1.5 to $35 \mathrm{mg} / \mathrm{dl}($ mean $=11.3 \mathrm{mg} / \mathrm{dl}, n=7)$ to $536-648 \mathrm{mg} / \mathrm{dl}$ in the high expressor animals (Table II). Further evidence of apoE production was obtained by immunoblot analysis of mouse plasma (Fig. 3). Analysis of plasma from the apoEdeficient mice starting at day 4 after injection with rAdv.apoE revealed the $36-\mathrm{kD} \mathrm{E}$ apolipoprotein band which could be detected in decreasing intensity for up to $34 \mathrm{~d}$. Marked overexpression of apoE in the high expressor animal group was transient, with levels of apoE decreasing to the range of the low expressor group by $8-12 \mathrm{~d}$.

The plasma lipids and lipoproteins of the apoE-deficient mice injected with rAdv.apoE as compared with apoE-deficient animals injected with rAdv.luc and control mice are summarized in Table III. $4 \mathrm{~d}$ after injection of rAdv.apoE, the markedly hypercholesterolemic lipoprotein profile of the apoE-deficient mice was dramatically altered and was comparable with the lipoprotein profile in control mice. The total cholesterol values in rAdv.apoE-treated mice ranged from 80 to $137 \mathrm{mg} / \mathrm{dl}$ on day 4. Thus, a similar normalization of the lipoprotein profile was achieved in animals with apoE expression ranging from 1.5 to $35.0 \mathrm{mg} / \mathrm{dl}$, indicating that only $1-2 \mathrm{mg} / \mathrm{dl}$ of functional E apolipoprotein or $\sim 20 \%$ of normal plasma apoE levels was sufficient to achieve a physiological correction of the lipid abnormalities. No significant change in the lipoprotein profile was observed when the apoE-deficient mice were injected with rAdv.luc, indicating that injection of an adenovirus with an irrelevant transgene had no effect on the plasma lipids and lipoproteins in the apoE-deficient mice.

The FPLC profiles of the plasma lipoproteins of the apoEdeficient mice at day 4 after rAdv.apoE infusions are shown in Fig. 1, $C$ and $D$. The marked elevation of the cholesterol-rich VLDL and IDL in the apoE-deficient mice after rAdv.apoE injection was normalized to a profile that was similar to control mice with HDL as the major plasma lipoprotein. Immunoblot analysis of the individual fractions across the FPLC elution profile revealed the presence of apoE primarily in the apoA-I containing HDL FPLC fractions, indicating that apoE had been incorporated into the mouse plasma lipoproteins (Fig. 3, right lanes).

The duration of changes in the plasma lipids after rAdv.apoE infusion is illustrated in Fig. 4. The apoE-deficient mice receiving rAdv.apoE had a rapid decrease in total cholesterol by day 2 with a maximum correction at day 4 and then a gradual return toward baseline. By day 30 , the plasma cholesterol levels were still approximately half those of the untreated apoE-deficient mice. A reduction in plasma cholesterol persisted in the rAdv.apoE-injected mice for up to $60 \mathrm{~d}$, thus establishing the ability of the transgene to synthesize and secrete apoE in sufficient levels to modulate lipoprotein metabolism. The animals with transient marked overexpression of apoE had similar cholesterol reduction (total cholesterol $=161 \mathrm{mg} / \mathrm{dl}$ on day 8 ) and expression as the low expressor group with plasma cholesterol returning toward baseline by day 46 .

To determine the effect of apoE gene replacement on spontaneous atherosclerosis, apoE-deficient mice were killed, and aortic atherosclerotic lesion areas were examined and quantitated histologically. Previous analyses of atherosclerotic lesion development in apoE-deficient mice in our laboratory demonstrated initial aortic lesions forming at 3 mo of age with rapid progression to complex atherosclerotic lesions by $5 \mathrm{mo}$ of age (data not shown) consistent with animals analyzed in previously reported studies $(20,21)$. Therefore, 4-mo-old male animals with aortic atherosclerotic lesion area of $\sim 30 \times 10^{3} \mu \mathrm{m}^{2}$ were chosen for the study and remained on a normal chow diet $(4.5 \%$ fat, $0 \%$ cholesterol) during the study. apoE-deficient mice had a mean lesion area per section of $136 \pm 18 \times 10^{3} \mu \mathrm{m}^{2}( \pm \mathrm{SEM}$; $n=15$ sections from three animals) at 5 mo of age (Fig. 5). As previously described $(20,21)$, these animals had characteristic atherosclerotic lesions that started in the aortic sinus and ex-

Figure 6. Proximal aortic sections from apoE-deficient mice. All sections were stained with Oil-red-O and hematoxylin and then counterstained with light green. Sections from an apoE-deficient mouse at 5 mo of age are on the left; sections from an apoE-deficient mouse at 5 mo of age after receiving rAdv.apoE 1 mo before on the right. The apoE-deficient animal has significant atherosclerotic changes with marked lipid accumulation and fibrosis $(A$ and $B$ ). An animal of the same age after rAdv.apoE treatment has an absence of complex lesion development with minimal lipid staining of the intima $(C$ and $D) . A$ and $C, \times 30 ; B$ and $D, \times 75$. 

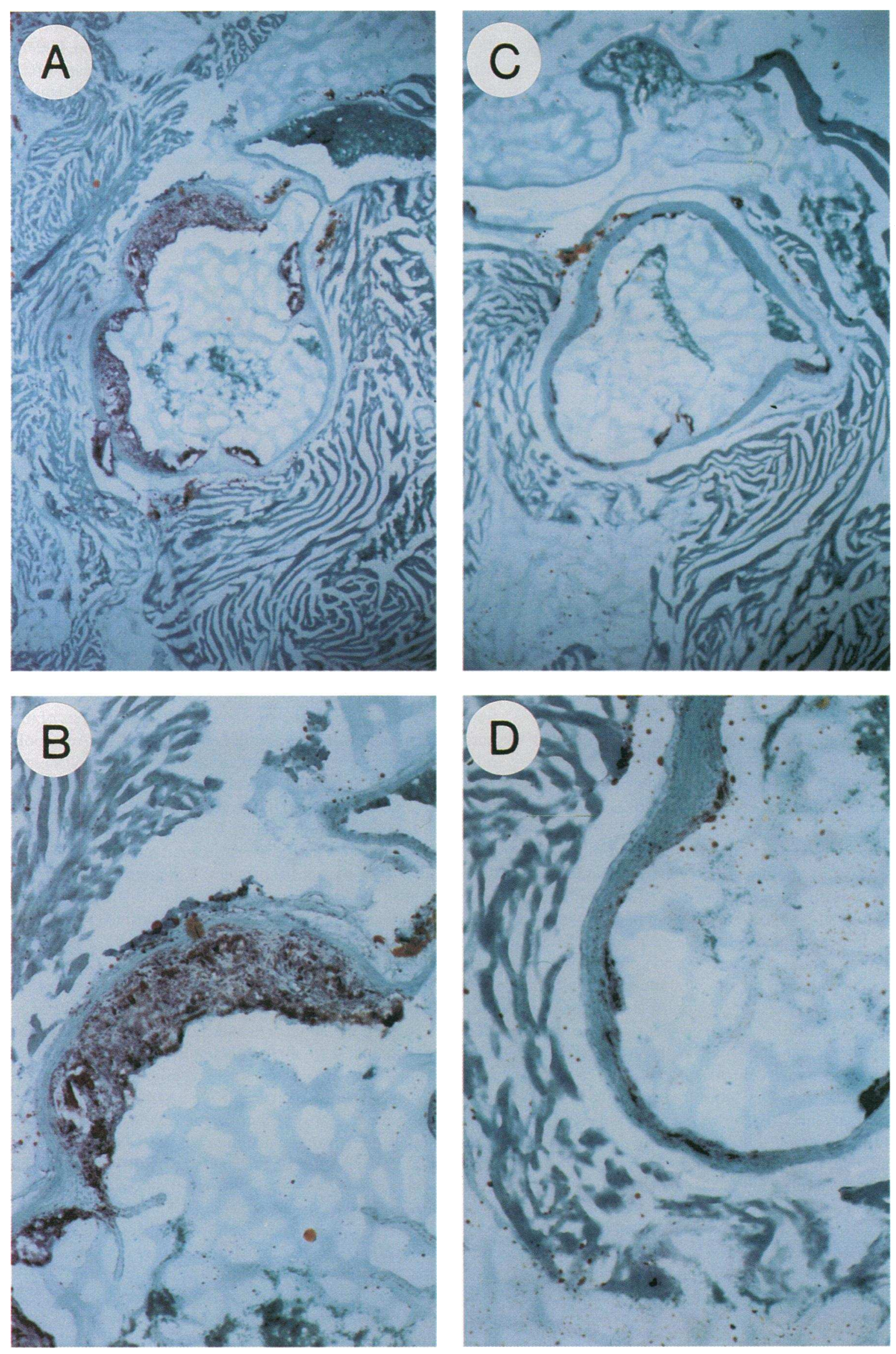
tended distally along the ascending aorta in all sections examined. The raised lesions had marked red staining areas using Oil-red-O indicating lipid accumulation with lipid-laden macrophages, extracellular lipid deposits, necrosis, and fibrosis (Fig. $6, A$ and $B$ ). Another subset of 4-mo-old apoE-deficient mice was infused with either rAdv.luc or rAdv.apoE and then killed 4 wk later at 5 mo of age. The rAdv.luc-infused mice had a mean lesion area per section of $161 \pm 19 \times 10^{3} \mu \mathrm{m}^{2}(n=15$ sections from three animals) and had lesions similar to control apoE-deficient mice. However, apoE-deficient animals expressing apoE had mean aortic lesion areas that were significantly smaller $\left(58 \pm 8 \times 10^{3} \mu \mathrm{m}^{2} ; n=20\right.$ sections from four animals; $P<0.0001$ ) than the animals infused with rAdv.luc (Fig. 5). The aortas from the apoE-treated mice showed minimal lipid staining and an absence of complex lesion formation (Fig. 6, $C$ and $D$ ) similar to younger animals.

\section{Discussion}

During the last two decades, there have been major advances in our understanding of the molecular defects that result in the genetic dyslipoproteinemias. In addition, several different dyslipoproteinemic animal model systems have been developed in mice by gene deletion using homologous recombination. Genetic defects in the plasma apolipoproteins are a frequent cause of the human genetic dyslipoproteinemias. The plasma apolipoproteins function in lipoprotein metabolism as cofactors for enzymes, structural proteins for lipoprotein biosynthesis, and ligands for interactions with lipoprotein receptors. Structural defects in apolipoprotein genes result in clinical phenotypes with characteristic changes in the plasma lipoproteins. The genetic dyslipoproteinemias are ideal candidates for gene therapy since the molecular defects in the genes have been established definitively and many of the diseases have significant sequelae to warrant treatment including premature cardiovascular and peripheral vascular disease or recurrent pancreatitis and pancreatic insufficiency (1).

In this study, we have selected the apoE-deficient mouse to determine the feasibility of apolipoprotein gene replacement in the genetic dyslipoproteinemias. To achieve an effective correction of the gene defect in the apoE-deficient animals, the apoE transgene must be expressed, apoE must be secreted from the liver, and the protein must associate with hepatic proteoglycans as well as plasma lipoproteins. The role of apoE in lipoprotein remnant clearance is to serve as a ligand on hepatic proteoglycans for the initial interaction of the lipoprotein particle with the cell after which there is an apoE-mediated specific interaction with the membrane lipoprotein receptors (3-8). As reviewed above, the apoE transgene must be expressed in the milligrams per deciliter range to achieve plasma levels similar to those present in humans and normal mice. Previous studies have demonstrated that intravenous delivery of recombinant adenovirus results in the expression of apoA-I (42) and Factor IX (40) in normal mice as well as successful correction of the metabolic defects associated with ornithine transcarbamylase (43) and LDL-receptor deficiency (41) in two mouse models for these genetic disorders. However, milligrams/deciliter levels of transgene expression associated with complete correction of a genetic disease have not been consistently achieved in most in vivo adenoviral gene therapy studies in mice (40-44). One of the major limitations of the currently used adenovirus vector system is the short-term expression of the transgene $(40,41$, 45-48) which in most cases is limited to less than 2 mo. Recent data suggest that this limited expression is due at least in part to the development of an immune response directed against viral late gene proteins that continue to be expressed with the current generation of adenovirus vectors $(43,49)$. Interestingly, despite the ability of the adenovirus vectors to transduce a wide variety of cells $(28,43,50-55)$, intravenous infusion appears to preferentially target the liver, the major site of synthesis of plasma lipoproteins and apoE $(40,42,43)$. Thus, we used recombinant adenovirus to evaluate the feasibility of correcting the marked hyperlipidemia and atherosclerosis in apoE-deficient mice after transient delivery of the human apoE gene to the liver.

Using the replication-deficient adenovirus vector system, we have achieved complete correction of the hypercholesterolemic lipoprotein profile in the apoE-deficient mouse. Plasma cholesterol levels were reduced from the $650 \mathrm{mg} / \mathrm{dl}$ range to the $100-$ $150 \mathrm{mg} / \mathrm{dl}$ levels of control mice. apoE could be detected in plasma by immunoblot analysis and by ELISA, and both low as well as high plasma levels of apoE associated primarily with mouse HDL were achieved. Interestingly, near the completion of our studies, Stevenson et al. reported (56) the lipoprotein profile observed after adenovirus-mediated gene transfer in apoE-deficient mice and indicated that the majority of expressed apoE associated with VLDL. However, in their study, an adenoviral construct with a Rous sarcoma virus (RSV) promoter was used resulting in apoE expression in the range of $0.12 \mathrm{mg} /$ dl. This level of apoE expression did not result in complete normalization of the elevated plasma VLDL when analyzed by FPLC, and the expressed apoE was associated with the cholesterol-rich VLDL. In contrast, in our report, FPLC analysis of the plasma lipoproteins of the apoE-deficient mice after rAdv.apoE infusion revealed a virtual complete shift from the cholesterolrich VLDL and IDL to HDL, the predominant lipoprotein characteristic of normal mice. The expressed apoE was associated primarily with HDL in our studies. Expression of the transgene was detected up to 1 mo after adenoviral injection and was accompanied by persistent cholesterol reduction.

Since most strains of mice are resistant to atherosclerosis, atherogenic diets to induce the development of atherosclerotic lesions have been needed in previous studies $(38,57)$. However, in the apoE-deficient animal, lesions form even when the animals are fed a normal chow diet. The effect of correction of the apoE gene defect on the development of this spontaneous atherosclerosis in the apoE-deficient mouse was determined in apoE-deficient mice $4 \mathrm{wk}$ after $\mathrm{rAdv}$.apoE infusion. The expression of apoE and correction of the hyperlipidemia for up to 4 wk after apoE gene replacement were sufficient enough to significantly reduce atherosclerosis in apoE-deficient mice. These animals demonstrated a significant decrease in the mean lesion area in the aortas when compared with control apoEdeficient mice infused with rAdv.luc or left untreated. Comparison of lesion area in 4-mo-old apoE-deficient mice and the rAdv.apoE-treated apoE-deficient animals suggests that the significant reduction in atherosclerosis in the latter group primarily reflects the prevention of progressive lesion formation rather than regression. This is consistent with the observation that, compared with the control groups, the rAdv.apoE-infused apoEdeficient animals had lesions with minimal lipid staining of the intima and no evidence of prior fibrosis. Presently, no practical 
noninvasive method exists to assess the baseline atherosclerosis before adenoviral infusion in each individual animal to definitively document regression of atherosclerotic lesions. However, older animals with more advanced lesions may be useful in subsequent studies to assess regression of atherosclerosis with transient apoE expression. Of major importance, however, is the finding that adenovirus-mediated transient expression of apoE resulted in modification of a major, complex clinical end point, atherosclerosis, in adult apoE-deficient mice.

These combined results provide definitive evidence that marked hyperlipidemia and atherosclerosis resulting from a molecular defect in a plasma apolipoprotein can be effectively corrected by adenovirus-mediated gene therapy. Based on these studies, we propose that the combined use of adenovirus vectors and the apoE-deficient mouse may provide a new and novel approach for the rapid screening of candidate genes for prevention of atherosclerosis.

\section{Acknowledgments}

The authors thank Dr. Frank L. Graham for providing the plasmid vectors pJM17 and pXCX2 for utilization in this study and Cynthia McFarland for providing excellent technical assistance.

This work was supported in part by NIH grant HL-32087 (B. Paigen).

\section{References}

1. Brewer, H. B., Jr., R. E. Gregg, and J. M. Hoeg. 1989. Apolipoproteins, lipoproteins, and atherosclerosis. In Heart Disease: A Textbook of Cardiovascular Medicine. E. Braunwald, editor. W. B. Saunders, Co., New York. 121-144.

2. Mahley, R. W. 1988. Apolipoprotein E: cholesterol transport protein with expanding role in cell biology. Science (Wash. DC). 240:622-630.

3. Mahley, R. W., T. L. Innerarity, K. H. Weisgraber, S. C. Rall, Jr., D. Y. Hui, A. Lalazar, J. K. Boyles, J. M. Taylor, and B. Levy-Wilson. 1986. Cellular and molecular biology of lipoprotein metabolism: characterization of lipoprotein receptor-ligand interactions. Cold Spring Harbor Symp. Quant. Biol. 51:821-828.

4. Nykjaer, A., G. Bengtsson-Olivecrona, A. Lookene, S. K. Moestrup, C. M Petersen, W. Weber, U. Beisiegel, and J. Gliemann. 1993. The $\alpha_{2}$-macroglobulin receptor/low density lipoprotein receptor-related protein binds lipoprotein lipase and $\beta$-migrating very low density lipoprotein associated with the lipase. J. Biol. Chem. 268:15048-15055.

5. Mulder, M., P. Lombardi, H. Jansen, T. J. C. Van Berkel, R. R. Frants, and L. M. Havekes. 1993. Low density lipoprotein receptor internalizes low density and very low density lipoproteins that are bound to heparan sulfate proteoglycans via lipoprotein lipase. J. Biol. Chem. 268:9369-9375.

6. Mahley, R. W. Z S. Ji, W. J. Brecht, R. D. Miranda, and D. He 1994 Role of heparan sulfate proteoglycans and the LDL receptor-related protein in remnant lipoprotein metabolism. Ann. NY Acad. Sci. 737:39-52.

7. Santamarina-Fojo, S., and K. Dugi. 1994. Structure, function and role of lipoprotein lipase in lipoprotein metabolism. Curr. Opin. Lipidol. 5:117-125.

8. Takahashi, S., Y. Kawarabayasi, T. Nakai, J. Sakai, and T. Yamamoto 1992. Rabbit very low density lipoprotein receptor: a low density lipoprotein receptor-like protein with distinct ligand specificity. Proc. Natl. Acad. Sci. USA. 89:9252-9256.

9. Ghiselli, G., E. J. Schaefer, P. Gascon, and H. B. Brewer, Jr. 1981. Type III hyperlipoproteinemia associated with apolipoprotein E deficiency. Science (Wash. DC). 214:1239-1241.

10. Schaefer, E. J., R. E. Gregg, G. Ghiselli, T. M. Forte, J. M. Ordovas, L. A. Zech, and H. B. Brewer, Jr. 1986. Familial apolipoprotein E deficiency. $J$. Clin. Invest. 78:1206-1219.

11. Mabuchi, H., H. Itoh, M. Takeda, K. Kajinami, T. Wakasugi, J. Koizumi, R. Takeda, and C. Asagami. 1989. A young type III hyperlipoproteinemic patient associated with apolipoprotein E deficiency. Metab. Clin. Exp. 38:115-119.

12. Kurosaka, D., T. Teramoto, T. Matsushima, T. Yokoyama, A. Yamada, T. Aikawa, Y. Miyamoto, and K. Kurokawa. 1991. Apolipoprotein E deficiency with a depressed mRNA of normal size. Atherosclerosis. 88:15-20.

13. Lohse, P., H. B. Brewer III, M. S. Meng, S. I. Skarlatos, J. C. LaRosa and H. B. Brewer, Jr. 1992. Familial apolipoprotein E deficiency and type III hyperlipoproteinemia due to a premature stop codon in the apolipoprotein $\mathrm{E}$ gene. J. Lipid Res. 33:1583-1590.
14. Zannis, V. I., and J. L. Breslow. 1980. Characterization of a unique human apolipoprotein E variant associated with type III hyperlipoproteinemia. J. Biol. Chem. 255:1759-1762.

15. Brewer, H. B., Jr., L. A. Zech, R. E. Gregg, D. Schwartz, and E. J. Schaefer. 1983. Type III hyperlipoproteinemia: diagnosis, molecular defects, pathology, and treatment. Ann. Intern. Med. 98:623-640.

16. Brewer, H. B., Jr., S. Santamarina-Fojo, and J. M. Hoeg. 1995. Disorders of lipoprotein metabolism. In Endocrinology. L. J. DeGroot, M. Besser, J. L. Jameson, D. Loriaux, J. C. Marshall, W. D. Odell, J. T. Potts, Jr., A. H. Rubenstein, G. F. Cahill, Jr., L. Martini, and D. H. Nelson, editors. W. B. Saunders Company; Philadelphia. 2731-2753.

17. Mahley, R. W., and S. C. Rall, Jr. 1995. Type III hyperlipoproteinemia (dysbetalipoproteinemia): the role of apolipoprotein $\mathrm{E}$ in normal and abnormal lipoprotein metabolism. In The Metabolic and Molecular Bases of Inherited Disease. C. R. Scriver, A. L. Beaudet, W. S. Sly, D. Valle, J. B. Stanbury, J. B. Wyngaarden, and D. S. Fredrickson, editors. McGraw-Hill, Inc., New York. 1953-1980.

18. Thomas, K. R., and M. R. Capecchi. 1987. Site-directed mutagenesis by gene targeting in mouse embryo-derived stem cells. Cell. 51:503-512.

19. Piedrahita, J. A., S. H. Zhang, J. R. Hagaman, P. M. Oliver, and N. Maeda. 1992. Generation of mice carrying a mutant apolipoprotein $\mathrm{E}$ gene inactivated by gene targeting in embryonic stem cells. Proc. Natl. Acad. Sci. USA. 89:44714475 .

20. Plump, A. S., J. D. Smith, T. Hayek, K. Aalto-Setal̈a, A. Walsh, J. G. Verstuyft, E. M. Rubin, and J. L. Breslow. 1992. Severe hypercholesterolemia and atherosclerosis in apolipoprotein E-deficient mice created by homologous recombination in ES cells. Cell. 71:343-353.

21. Zhang, S. H., R. L. Reddick, J. A. Piedrahita, and N. Maeda. 1992 Spontaneous hypercholesterolemia and arterial lesions in mice lacking apolipoprotein E. Science (Wash. DC). 258:468-471.

22. Breslow, J. L. 1993. Transgenic mouse models of lipoprotein metabolism and atherosclerosis. Proc. Natl. Acad. Sci. USA. 90:8314-8318.

23. Linton, M. F., J. B. Atkinson, and S. Fazio. 1995. Prevention of atherosclerosis in apolipoprotein E deficient mice by bone marrow transplantation. Science (Wash. DC). 267:1034-1037.

24. Reue, K. L., D. H. Quon, K. A. O’Donnell, G. J. Dizikes, G. C. Fareed, and A. J. Lusis. 1984. Cloning and regulation of messenger RNA for mouse apolipoprotein E. J. Biol. Chem. 259:2100-2107.

25. Breslow, J. L., J. McPherson, A. L. Nussbaum, H. W. Williams, F. Lofquist-Kahl, S. K. Karathanasis, and V. I. Zannis. 1982. Identification and DNA sequence of a human apolipoprotein E cDNA clone. J. Biol. Chem. 257:1463914641.

26. Paik, Y. K., D. J. Chang, C. A. Reardon, G. E. Davies, R. W. Mahley, and J. M. Taylor. 1985. Nucleotide sequence and structure of the human apolipoprotein E gene. Proc. Natl. Acad. Sci. USA. 82:3445-3449.

27. Sanger, F., and A. R. Coulson. 1975. A rapid method for determining sequences in DNA by primed synthesis with DNA polymerase. J. Mol. Biol. 94:441-448.

28. Graham, F. L., J. Smiley, W. C. Russel, and R. Nairn. 1977. Characteristics of a human cell line transformed by DNA from human adenovirus type 5. J. Gen. Virol. 36:59-72.

29. Chen, C., and H. Okayama. 1987. High-efficiency transformation of mammalian cells by plasmid DNA. Mol. Cell. Biol. 7:2745-2752.

30. Berkner, K. L. 1988. Development of adenovirus vectors for the expression of heterologous genes. Bio Techniques. 6:616-629.

31. McGrory, W. J., D. S. Bautista, and F. L. Graham. 1988. A simple technique for the rescue of early region 1 mutations into infectious human adenovirus type 5. Virology. 163:614-617.

32. de Wet, J. R., K. V. Wood, M. DeLuca, D. R. Helinski, and S. Subramani. 1987. Firefly luciferase gene: structure and expression in mammalian cells. Mol. Cell. Biol. 7:725-737.

33. Committee on Care and Use of Laboratory Animals. 1985. NIH Guide for the Care and Use of Laboratory Animals. NIH Publication, Bethesda, MD.

34. Gould, S. J., and S. Subramani. 1988. Firefly luciferase as a tool in molecular and cell biology. Anal. Biochem. 175:5-13.

35. Mackness, M. I., and P. N. Durrington. 1992. Lipoprotein separation and analysis for clinical studies. In Lipoprotein Analysis: A Practical Approach. C. A Converse and E. R. Skinner, editors. IRL Press, New York. 1-42.

36. Jiao, S., T. G. Cole, R. T. Kitchens, B. Pfleger, and G. Schonfeld. 1990 Genetic heterogeneity of lipoproteins in inbred strains of mice: analysis by gelpermeation chromatography. Metab. Clin. Exp. 39:155-160.

37. Paigen, B., A. Morrow, P. A. Holmes, D. Mitchell, and R. A. Williams 1987. Quantitative assessment of atherosclerotic lesions in mice. Atherosclerosis. 68:231-240.

38. Paigen, B., B. Y. Ishida, J. Verstuyft, R. B. Winters, and D. Albee. 1990. Atherosclerosis susceptibility differences among progenitors of recombinant inbred strains of mice. Arteriosclerosis. 10:316-323.

39. Mittal, S. K., M. R. McDermott, D. C. Johnson, L. Prevec, and F. L. 
Graham. 1993. Monitoring foreign gene expression by a human adenovirus-based vector using the firefly luciferase gene as a reporter. Virus Res. 28:67-90.

40. Smith, T. A. G., M. G. Mehaffey, D. B. Kayda, J. M. Saunders, S. Yei, B. C. Trapnell, A. McClelland, and M. Kaleko. 1993. Adenovirus mediated expression of therapeutic plasma levels of human factor IX in mice. Nat. Genet. 5:397-402.

41. Ishibashi, S., M. S. Brown, J. L. Goldstein, R. D. Gerard, R. E. Hammer, and J. Hertz. 1993. Hypercholesterolemia in low density lipoprotein receptor knockout mice and its reversal by adenovirus-mediated gene delivery. J. Clin. Invest. 92:883-893.

42. Kopfler, W. P., M. Willard, T. Betz, J. E. Willard, R. D. Gerard, and R. S. Meidell. 1994. Adenovirus-mediated transfer of a gene encoding human apolipoprotein A-I into normal mice increases circulating high-density lipoprotein cholesterol. Circulation. 90:1319-1327.

43. Stratford-Perricaudet, L. D., M. Levrero, J. Chasse, M. Perricaudet, and P. Briand. 1990. Evaluation of the transfer and expression in mice of an enzymeencoding gene using a human adenovirus vector. Hum. Gene Ther. 1:241-256.

44. Descamps, V., N. Blumenfeld, J. L. Villeval, W. Vainchenker, M. Perricaudet, and Y. Beuzard. 1994. Erythropoietin gene transfer and expression in adult normal mice: use of an adenovirus vector. Hum. Gene Ther. 5:979-985.

45. Jaffe, H. A., C. Danel, G. Longenecker, M. Metzger, Y. Steoguchi, M. A. Rosenfeld, T. W. Gant, S. S. Thorgeirsson, L. D. Stratford-Perricaudet, M. Perricaudet, et al. 1992. Adenovirus-medicated in vivo gene transfer and expression in normal rat liver. Nat. Genet. 1:372-378.

46. Li, Q., M. A. Kay, M. Finegold, L. D. Stratford-Perricaudet, and S. L. C. Woo. 1993. Assessment of recombinant adenoviral vectors for hepatic gene therapy. Hum. Gene Ther. 4:403-409.

47. Engelhardt, J. F., R. H. Simon, Y. Yang, M. Zepeda, S. Weber-Pendleton, B. Doranz, M. Grossman, and J. M. Wilson. 1993. Adenovirus-mediated transfer of the CFTR gene to lung of nonhuman primates: biological efficacy study. Hum. Gene Ther. 4:759-769.
48. Simon, R. H., J. F. Engelhardt, Y. Yang, M. Zepeda, S. Weber-Pendleton, M. Grossman, and J. M. Wilson. 1993. Adenovirus-mediated transfer of the CFTR gene to lung of nonhuman primates: toxicity study. Hum. Gene Ther. 4:771-780.

49. Yang, Y., F. A. Nunes, K. Berencsi, E. E. Furth, E. Gonczol, and J. M. Wilson. 1994. Cellular immunity to viral antigens limits E1-deleted adenoviruses for gene therapy. Proc. Natl. Acad. Sci. USA. 91:4407-4411.

50. Rosenfeld, M. A., W. Siegfried, K. Yoshimura, K. Yoneyama, M. Fukayama, L. E. Stier, P. K. Paakko, P. Gilardi, L. D. Stratford-Perricaudet, M. Perricaudet, et al. 1991. Adenovirus-mediated transfer of a recombinant alpha 1-antitrypsin gene to the lung epithelium in vivo. Science (Wash. DC). 252:431-434.

51. Quantin, B., L. D. Perricaudet, S. Tajbakhsh, and J. L. Mandel. 1992. Adenovirus as an expression vector in muscle cells in vivo. Proc. Natl. Acad. Sci. USA. 89:2581-2584.

52. Lemarchand, P., H. A. Jaffe, C. Danel, M. C. Cid, H. K. Kleinman, L. D. Stratford-Perricaudet, M. Perricaudet, A. Pavirani, J.-P. Lecocq, and R. G. Crystal. 1992. Adenovirus-mediated transfer of a recombinant human alpha 1-antitrypsin cDNA to human endothelial cells. Proc. Natl. Acad. Sci. USA. 89:6482-6486.

53. Le Gal La Salle, G., J. J. Robert, S. Berrard, V. Ridoux, L. D. StratfordPerricaudet, M. Perricaudet, and J. Mallet. 1993. An adenovirus vector for gene transfer into neurons and glia in the brain. Science (Wash. DC). 259:988-990.

54. Bennett, J., J. Wilson, D. Sun, B. Forbes, and A. Maguire. 1994. Adenovirus vector-mediated in vivo gene transfer into adult murine retina. Invest. Ophthalmol. \& Visual Sci. 35:2535-2542.

55. Roessler, B. J., E. D. Allen, J. M. Wilson, J. W. Hartman, and B. L. Davidson. 1993. Adenoviral-medicated gene transfer to rabbit synovium in vivo. J. Clin. Invest. 92:1085-1092.

56. Stevenson, S. C., J. Marshall-Neff, B. Teng, C. B. Lee, S. Roy, and A. McClelland. 1995. Phenotypic correction of hypercholesterolemia in apoE-deficient mice by adenovirus mediated in vivo gene transfer. Arterioscler. Thromb. Vasc. Biol. 15:479-484.

57. Nishina, P. M., J. Verstuyft, and B. Paigen. 1990. Synthetic low and high fat diets for the study of atherosclerosis in the mouse. J. Lipid Res. 31:859-869. 